\title{
PPARy/Pgc-1a-Fndc5 pathway up- regulation in gastrocnemius and heart muscle of exercised, branched chain amino acid diet fed mice
}

Navid Abedpoor ${ }^{1}$, Farzaneh Taghian ${ }^{1 *}$, Kamran Ghaedi ${ }^{2,3^{*}}$ (1), Iman Niktab ${ }^{3}$, Zahra Safaeinejad ${ }^{3}$, Farzaneh Rabiee ${ }^{3}$, Sommayeh Tanhaei ${ }^{3}$ and Mohammad Hossein Nasr-Esfahani ${ }^{3^{*}}$

\begin{abstract}
Background: Previous studies have revealed the inductive effect of branched-chain amino acids (BCAAs) catabolism on fatty acid oxidation and metabolism, especially in muscle cells. In the present investigation, we have attempted to address whether a combination of BCAAs supplement consumption with aerobic exercise could elaborate the expression of PPARY, Pgc-1a and Fndc5 genes in gastrocnemius muscle and heart tissue of male C57BL/6 mice.

Methods: Thirty-six young male mice with an average weight of $18 \pm 2 \mathrm{~g}$ were selected. Mice were randomly assigned to 6 groups: $20 \mathrm{mg} / \mathrm{mL}$ of BCAAs consumption with simultaneous exercise-training, $60 \mathrm{mg} / \mathrm{mL}$ of BCAAs consumption with simultaneous exercise-training, exercise-trained with no BCAAs consumption group, $20 \mathrm{mg} / \mathrm{mL}$ BCAAs without exercise-training, $60 \mathrm{mg} / \mathrm{mL}$ BCAAs without exercise-training, and untrained mice without BCAAs consumption.

Results: The findings showed a combination of $20 \mathrm{mg} / \mathrm{mL}$ BCAAs with aerobic exercise significantly increased Fndc5, PPARY, Pgc-1a gene expression in skeletal muscles although, circulating Irisin levels remained unchanged $(p<0.05)$. Interestingly, plasma urea and lactate levels were significantly increased in $60 \mathrm{mg} / \mathrm{mL}$ BCAAs administrated mice which performed exercised $(p<0.05$ ). Two-way analysis of variance (ANOVA) was used to examine significant difference between groups and sedentary group.

Conclusions: Results showed inductive effect of $20 \mathrm{mg} / \mathrm{mL}$ BCAAs on expression levels of Fndc5, PPARY, Pgc-1a in gastrocnemius muscle similar with counterparts in heart tissue. Of note, higher serum irisin levels were detected after $20 \mathrm{mg} / \mathrm{mL}$ BCAAs supplementation coincided with the exercise.
\end{abstract}

Keywords: Aerobic exercise, Branched-chain amino acids, Catabolism, Fndc5, Irisin, Pgc-1a, PPARY

\footnotetext{
*Correspondence: F_taghian@yahoo.com; kamranghaedi@yahoo.com; mh.nasr-esfahani@royaninstitute.org

'Department of Physical Education and Sports Science, Isfahan (Khorasgan) Branch, Islamic Azad University, Isfahan, Iran

${ }^{2}$ Department of Biology, Faculty of Sciences, University of Isfahan, Isfahan, Iran

${ }^{3}$ Department of Cellular Biotechnology, Cell Science Research Center, Royan Institute for Biotechnology, ACECR, Royan Street, Salman Street, Isfahan 816513-1378, Iran
}

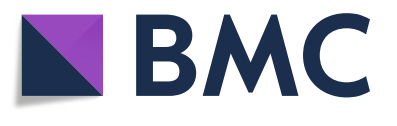

(c) The Author(s). 2018 Open Access This article is distributed under the terms of the Creative Commons Attribution 4.0 International License (http://creativecommons.org/licenses/by/4.0/), which permits unrestricted use, distribution, and reproduction in any medium, provided you give appropriate credit to the original author(s) and the source, provide a link to the Creative Commons license, and indicate if changes were made. The Creative Commons Public Domain Dedication waiver (http://creativecommons.org/publicdomain/zero/1.0/) applies to the data made available in this article, unless otherwise stated. 


\section{Background}

Branched Chain Amino Acids (BCAAs), including Leucine, Isoleucine, and Valine, are essential amino acids that body is unable to synthesize and needs to be provided by the diet. BCAAs play a significant role in energy homeostasis as they are important for the maintenance of skeletal muscle [1]. Restorative effects of BCAAs on muscle soreness and fatigue are already well recognized $[2,3]$. A great proportion of BCAAs metabolism occurs in skeletal muscle, where metabolism is regulated. In muscle, BCAAs stimulate mammalian target of rapamycin complex 1 (mTORC1) and protein synthesis and inhibit protein catabolism [4-6]. Moreover, BCAAs improve aerobic capacity and threshold of anaerobic activities in human Previous studies have shown that consumption of BCAAs increases lipid metabolism and reduces concentration of skeletal muscle triglycerides Interestingly, dietary BCAAs supplementation has intensified lifetime via promotion of mitochondrial biogenesis and enhancement in Sirtuin 1 (Sirt1) expression besides a reduction in oxidative damage [7-11]. Therefore BCAAs can be beneficial for energy expenditure and health status.

Recent studies revealed substantial role of fibronectin type III domain containing 5 (FNDC5) and its secretory type, irisin, in energy metabolism and regulation [12, 13]. FNDC5 expression is induced by exercise [12, 13]. Huh et al. have shown that plasma irisin and expression of FNDC5 are increased in response to acute exercise [15]. Of significant worth is the positive association between oxidative components and ROS with irisin content in trained mice [16].

Another key player in regulation of metabolism is peroxisome proliferator-activated receptor gamma (PPAR $)$ / peroxisome proliferator-activated receptor gamma coactivator 1-alpha (Pgc-1 $\alpha)$ axis. Pgc-1 $\alpha$ stimulates the expression of nuclear respiratory factor (NRF), which leads to expression of mitochondrial transcription factor A (TFAM) and mitochondrial biogenesis. Pgc- $1 \alpha$ stimulates and promotes mitochondrial biogenesis and capillary density as well as exercise capacity $[10,17,18]$. Consequently, aerobic exercise, also could increase $P G C-1 \alpha$ expression [19]. Therefore it seems that there is a positive feedback on exercise capacity by PGC- $1 \alpha$.

Another key factor for promotion of mitochondrial biogenesis, oxidative capacity and preventing of the mitochondrial dysfunction in skeletal muscle is Sirt1 [20].

Also, up-regulation of mitochondrial biogenesis and increase in PGC-1 $\alpha$ expression have been shown in a previous study [10]. Moreover, Aydin et al. indicated cardiac muscle produces more irisin than skeletal muscle [21]. Furthermore, BCAAs supplementation has been indicated to lead an increment of performance in rats subjected to moderate-intensity training [3]. Thus, the aim of present study is determination of BCAAs supplementation effects in association with aerobic training on plasma irisin and expression of gastrocnemius muscle Fndc5, PPAR, Pgc-1 $\alpha$, Sirt1 in male C57BL/6 mice.

\section{Methods \\ Bioinformatics studies}

A list of BCAAs and FNDC5 related proteins were extracted by an intensive literature review and text mining from a period of 2013-2017 (list is not shown). This list was subjected to the STRING V10.5 (https://string-$\mathrm{db} . \mathrm{org} /$ ) web site [22].In order to obtain the maximal data of FNDC5 and related proteins network, a low confidence level $(>0.150)$ was set. Among the visual network, which was obtained, PPAR $\gamma$, Pgc-1 $\alpha$, Sirt1 were shown to be interacted with FNDC5 straightly. At the next step, STRING default confidential level was set to $>0.400$ (mid confidence level) in order to define the interactions of PPAR $\gamma, \operatorname{Pgc}-1 \alpha$, Sirt1 with other proteins. We also assessed similarity of studied protein network between human and mouse via STRING V10.5.

\section{Ethical issue}

Approval to perform experiments on mice was obtained by the ethics committee of Royan Institute (IR.ACECR. ROYAN.REC.1396.19).

\section{Animals and protocols}

Four-week old wild type male C57BL/6 mice, were provided by Royan Institute (Tehran, Iran). Mice were housed in a temperature controlled room $\left(24 \pm 3{ }^{\circ} \mathrm{C}\right)$ with a humidity of $65 \%( \pm 5 \%)$ and $12 \mathrm{~h}$ light $/ 12 \mathrm{~h}$ dark cycle (lights from 08:00 am to 8:00 pm). Mice were allowed to acclimate for two weeks prior to the start of the experiment. Mice at their 6th weeks of age with an approximate weight of $18 \pm 2 \mathrm{~g}$, were randomly divided into six groups $(N=6)$. The groups were: (20BCAA/Ex): supplemented with $20 \mathrm{mg} / \mathrm{mL}$ of BCAAs with simultaneous exercise-training; (60BCAA/Ex): supplemented with $60 \mathrm{mg} / \mathrm{mL}$ of BCAAs with simultaneous exercise-training; (Ex): nonsupplemented, undergoing exercise; (20BCAA): supplemented with $20 \mathrm{mg} / \mathrm{mL}$ BCAAs; (60BCAA): supplemented with $60 \mathrm{mg} / \mathrm{mL}$ BCAAs (Sed): untrained mice without BCAAs intake (Fig. 1).

\section{BCAAs supplementation and food intake}

Mice were fed with free access to standard food (13\% $(w / w)$ fat, $30 \%(\mathrm{w} / \mathrm{w})$ protein, $57 \%(\mathrm{w} / \mathrm{w})$ carbohydrate with a total $2900 \mathrm{kcal}$ ) and tap water. BCAAs (Bio nutrition, USA) were dissolved in distilled water and applied by gavage $(500 \mu \mathrm{L})$ once per day for 8 weeks $(20 \mathrm{mg} /$ $\mathrm{mL} /$ day for 20BCAA group and $60 \mathrm{mg} / \mathrm{mL} /$ day for 60BCAA group). The reason for selecting 20 and $60 \mathrm{mg} /$ $\mathrm{mL}$ of BCAAs was that $20 \mathrm{mg} / \mathrm{mL}$ of BCAAs was 


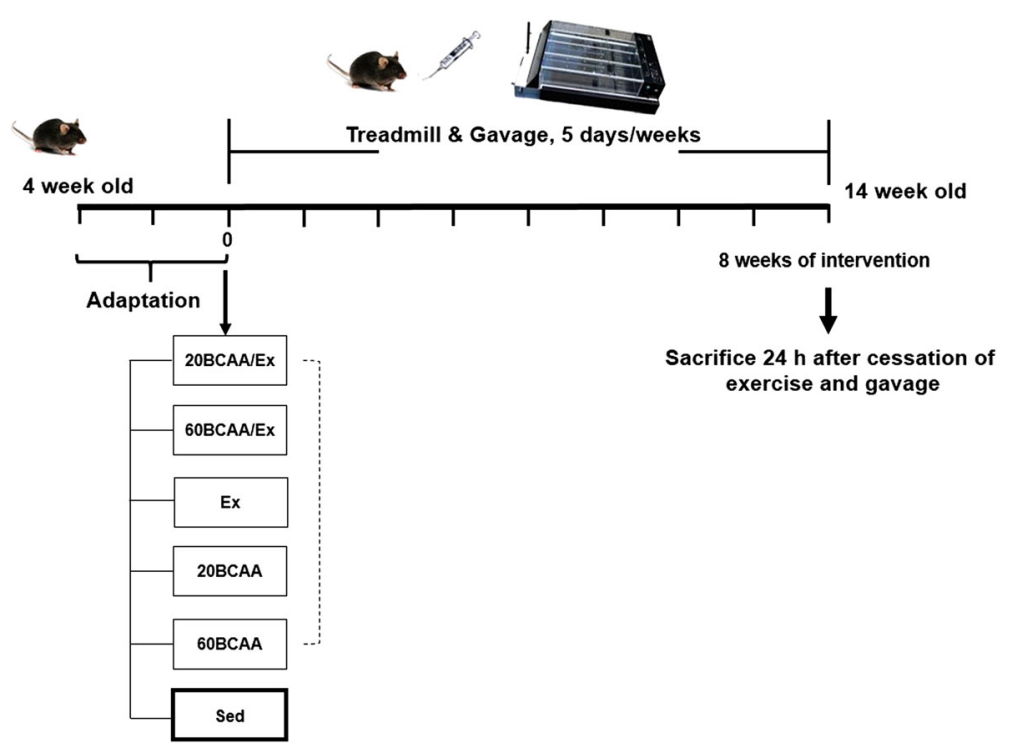

Fig. 1 Schematic representataion of protocol used for BCAAs supplementation and exercise. As depicted, acclimation was performed for two weeks. Then, mice were randomly divided to training $(n=6)$ and sedantry $(S e d ; n=6)$ groups. Training groups were EX as exercised group. 20BCAA and 60BCAA groups were mice supplemented with 20 and $60 \mathrm{mg} / \mathrm{mL}$ of BCAAs respectively. 20BCAA/EX and 60BCAA/EX were exercised groups supplemented with 20 and $60 \mathrm{mg} / \mathrm{mL}$ of BCAAs respectively. BCAAs supplementaion was performed by oral gavage (500 $\mu \mathrm{L}) 5$ days per week. On the other hand mice were excercised by placing on the motor-driven treadmill as described in materials and methods for 5 days per week. Exercise and BCAAs supplemention was carried out as an intervention for 8 weeks. One day after the final session of intervention (gavage or exercise), mice were sacrified for further experiments

already indicated to contain beneficial effects $[9,23]$. Therefore, $60 \mathrm{mg} / \mathrm{mL}$ of BCAAs (three times more concentrated dose) was considered as an overdose.

\section{Exercise training protocol, tolerance, and motor coordination tests}

Endurance exercise training (Ex) and exhaustion tests were performed on a motorized treadmill. Ex was performed briefly as a type of moderate-high intensity exercise on treadmill for 8 weeks (5 days/week). After being acclimated to treadmill exercises over two weeks, running speed and duration of exercise were progressively increased to reach $\sim 70 \% \mathrm{VO}_{2} \max (25 \mathrm{~m} / \mathrm{min})$. Whole exercise training was $45 \mathrm{~min}$. The grade of treadmill slope was set to $0 \%$ and the speed of treadmill was set to increase in a rate of $3 \mathrm{~m} / \mathrm{min}$, initiating from $10 \mathrm{~m} / \mathrm{min}$ to the final speed of $25 \mathrm{~m} / \mathrm{min}\left(\sim 70 \% \mathrm{VO}_{2} \max \right)$ [3, 19, 24]. Fixed speed rotarod was implemented to measure motor coordination and balance. Each mouse was received three trials per day for two consecutive days. The mice were trained at an initial constant speed of $8 \mathrm{rpm}$ for $5 \mathrm{~min}$. Then the speed was increased to $30 \mathrm{rpm}$ for $5 \mathrm{~min}$ and the latency to fall was recorded. Time score was measured as the mean of the best performances over the three trials at the second day [10]. After 8 weeks of exercise and oral consumption of BCAAs, mice were fasted for $7 \mathrm{~h}$ before euthanasia. Mice were euthanized under the combined administration of xylazine $(10 \mathrm{mg} / \mathrm{kg}$

Table 1 Primer list

\begin{tabular}{lllll}
\hline Gene & Forward primer $\left(5^{\prime}-3^{\prime}\right)$ & Reverse primer $\left(5^{\prime}-3^{\prime}\right)$ & Annealing temperature $\left({ }^{\circ} \mathrm{C}\right)$ & Accession no. \\
\hline Gapdh & TGCCGCCTGGAGAAAC & TGAAGTCGCAGGAGACAACC & 58.6 & NM_008084.2 \\
Pgc-1a & CCCTGCCATTGTAAGACC & TGCTGCTGTTCCTGTTTC & 52 & NM_008904.2 \\
Fndc5 & TCATTGTTGGGTCCTCTTC & GCTCGTTGTCTTGATGATA & 60 & NM_027402.3 \\
PPARY & TGAGACCAACAGCCTGAC & GTTCACCGCTTCTTCAAATC & 58 & NM_001127330.1 \\
ATP5a1 & TCCGCTTACATTCCAACA & ACACAGACAAACCCACAT & 54 & NM_007505.2 \\
ATP5b & GGTAGCGTTGGTATATGG & CTCCTGGTCTCTGAAGTA & 54 & NM_016774.3 \\
Cox4i1 & ATGGGAGTGTTGAAGAGT & CATCAGGCAAGGGGTAGT & 54 & NM_009941.3 \\
Tfam & CTTCAACCACCACACCACT & AATCTCTAAGCCTCCTCAATACAA & 56 & NM_009360.4 \\
Sirt1 & GGCAGTAACAGTGACAGT & CTCTCCGTATCATCTTCCAA & 61 & NM_001159589.2 \\
\hline
\end{tabular}




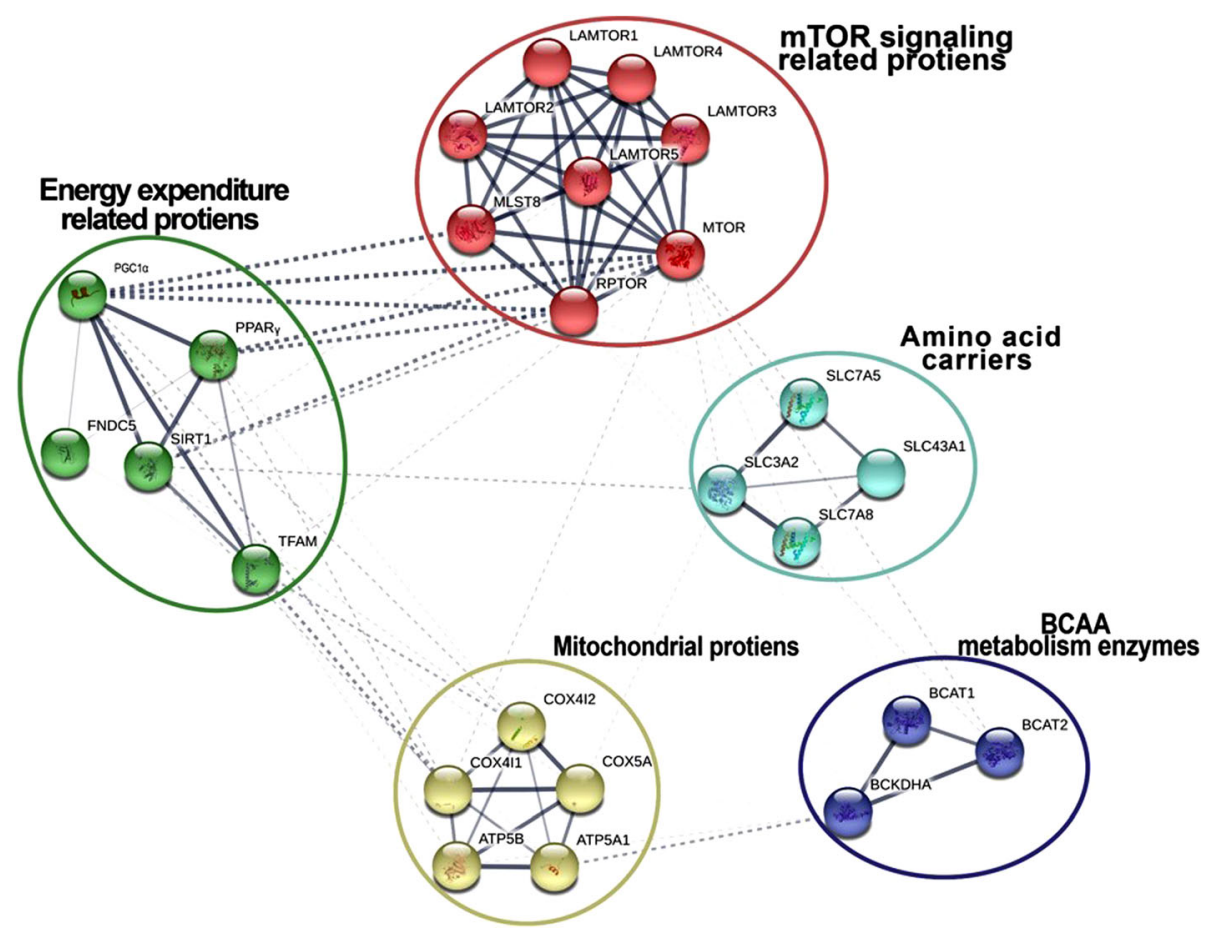

Fig. 2 STRING analysis to unravel interactions between FNDC5 with SIRT1, PPARY, Pgc-1a, and TFAM proteins in human. As detailed in materials and methods, low-confidence interactions in STRING (string-db.org) indicated interaction among SIRT1, PPARY, Pgc-1a, and TFAM proteins in mouse. TFAM and its downstream proteins including COX411, COX412, COX5A, ATP5A1, and ATP5B are shown. Also there were strong interactions with SIRT1, PPARY, Pgc-1a and mTOR signaling components as evidenced that mTOR components are regulated by BCAAs. Moreover, there is an evidence for interaction between proteins involved in BCAAs metabolism and ATP5A1 (a mitochondrial protein). This schematic representation evidences that there is a coordination between energy expenditure proteins and mTOR signaling components as well as amino acid carriers, mitochondrial proteins and enzymes in BCAAs metabolism

body weight per mouse) and ketamine $(80 \mathrm{mg} / \mathrm{kg}$ body weight per mouse) (Fig. 1).

\section{Quantitative real-time PCR (qRT-PCR)}

Total RNA was extracted from gastrocnemius muscle and heart using TRIzol reagent (Sigma, USA). Samples were treated with DNaseI (TaKaRa) to remove contaminating genomic DNA. cDNA synthesis was performed with $1 \mu \mathrm{g}$ of total RNA by cDNA synthesis kit according to the manufacturer's instruction (TaKaRa). qRT-PCR was carried out with CYBR green (TaKaRa, Japan) using Corbet rotor gene 6000 (Qiagen, Australia). Assessment of gene expression was performed according to $\Delta \Delta \mathrm{CT}$ method. Expression level of genes was reported relative to glyceraldehyde-3-phosphate dehydrogenase (Gapdh) expression level as already was implemented in similar studies [25-27].

Primers were ordered from micro-gene (South Korea) and their sequences are listed in Table 1.

\section{Protein extraction and western blotting}

Tissues were lysed using TRI reagent (Thermo Scientific, 15,596-018), according to the manufacturer protocol. Equal amounts of each protein sample $(30 \mu \mathrm{g})$ were separated by SDS- PAGE and transferred to PVDF membranes (Bio Rad, 162-0176). After blocking the membranes with $10 \%$ skim milk (Millipore, 115,363), membranes were incubated withdifferent primary antibodies for $2 \mathrm{~h}$ at room temperature. Primary antibodies were rabbit anti-FNDC5 antibody (1:2000, Abcam, AB174833) and mouse anti GAPDH antibody (1:5000, Santa Cruz). Then, membranes were incubated for $1 \mathrm{~h}$ at room temperaturewith an appropriate secondary antibody: horseradish peroxidase (HRP)-conjugated goat antimouse IgG (1:5000, Dako, P0447), or HRP-conjugated goat anti-rabbit IgG (1:16000, Santa Cruz, SC2301). HRP-conjugated IgG bound to each protein band was visualized by anAmersham ECL Advance Western Blotting Detection Kit (GE Healthcare). The intensity of each band was quantified by Image J software.

\section{Plasma measurement of irisin, urea and lactate}

Blood was collected from the right ventricle of each mouse and drawn into an EDTA containing tube. To separate plasma, blood containing tubes were centrifuged for $15 \mathrm{~min}$ at $1600 \times \mathrm{g}$ at $4{ }^{\circ} \mathrm{C}$. All samples were frozen in liquid nitrogen and stored at $-80{ }^{\circ} \mathrm{C}$ until 


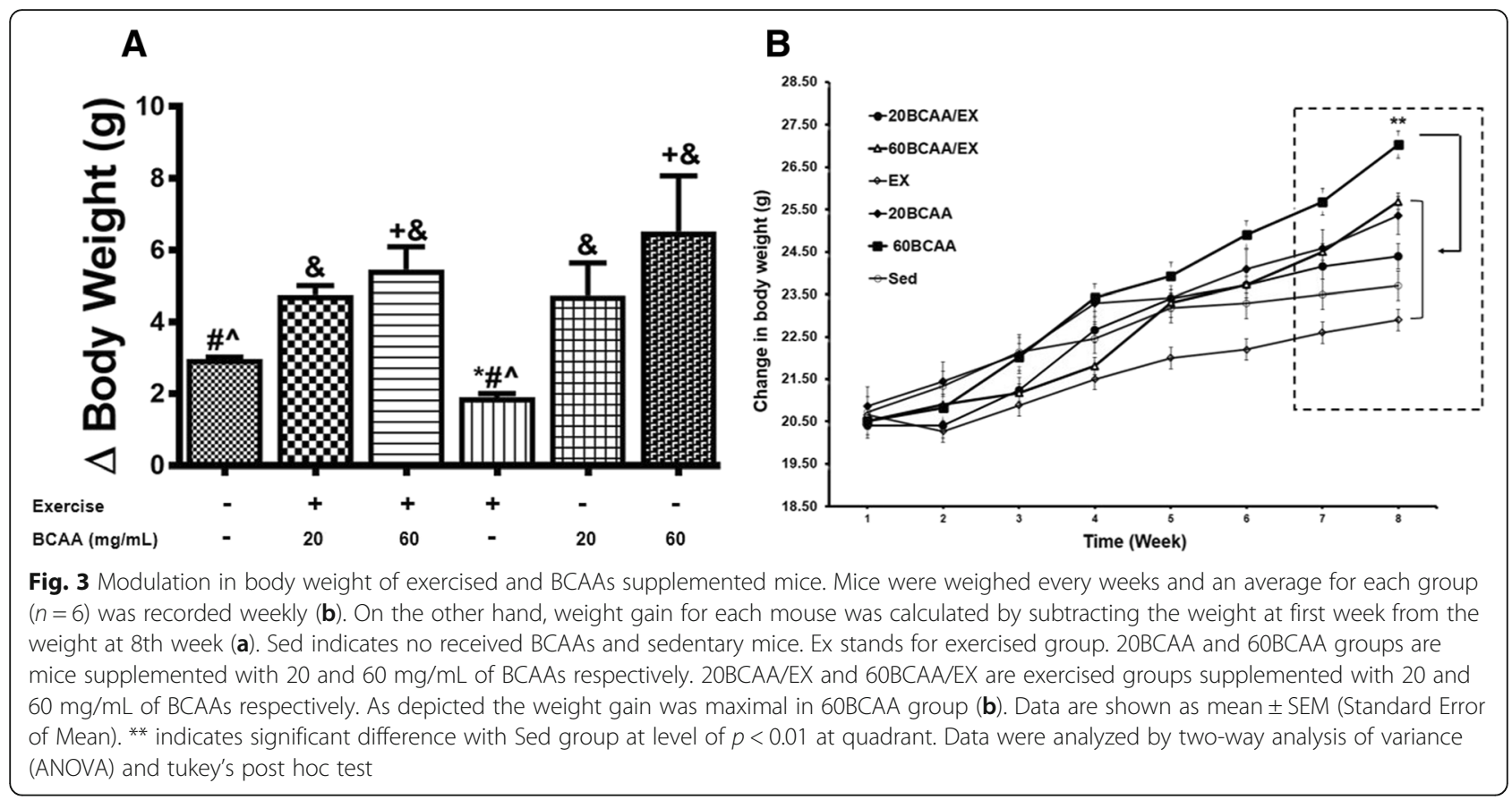

further use. Plasma irisin levels were measured using a commercially available enzyme-linked immunosorbent assay ELISA Kit (EK-067-29, Phoenix, USA). The assay kit was highly sensitive to irisin in mice and detection range of this kit was $0.1-1000 \mathrm{ng} / \mathrm{mL}$. Meanwhile, plasma urea concentration (Pars Azmon, Iran) and lactate (Biorex Fars, Iran) were measured according to the manufacturer's instructions.

\section{Statistical analysis}

Statistical analysis was performed using GraphPad Prism Software (Version 7.0a Graph Pad Software Inc., La Jolla, CA). Kolmogorov-Smirnov test was used for normalizing of distribution, and variables were normally distributed. Results are presented as mean \pm standard error of mean (SEM). Data of RT-qPCR and western blotting were obtained on triplicate data sets for each sample and analyzed by two-way analysis of variance (ANOVA) with tukey's post hoc test due to multiple comparisons. Differences at $p<0.05$ were considered to be significant in all analyses.

\section{Results}

Bioinformatics analyses indicated a connection ring of FNDC5 with SIRT1, PPARY, Pgc-1a, and TFAM

STRING low confidence level showed a text mining-based interaction between FNDC5 with SIRT1, PPAR $\gamma$ Pgc- $1 \alpha$, and TFAM (Fig. 2). Next, analyses of high-confidence interactions indicated a strong interaction among SIRT1, PPAR $\gamma$, Pgc- $1 \alpha$, and TFAM proteins (Data not shown). As
TFAM is in connection with mitochondrial DNA (mtDNA) replication and transcription activity, its downstream proteins including COX4I1, COX4I2, COX5A, ATP5A1 and ATP5B are also involved. Of important, there is a high similarity in protein sequences between human and mouse for a number of aforementioned proteins emphasizing similar text mining-based interactions between these proteins in human (Additional file 1: Figure S1) [22].

\section{Animal characteristics measurements}

Body weight (Fig. 3a, b) and gastrocnemius muscle weight (Table 2) were significantly increased in 60BCAA group.

Table 2 Heart and gastrocnemius muscle weight of mice

\begin{tabular}{|c|c|c|c|}
\hline \multicolumn{2}{|l|}{ Groups } & \multirow{2}{*}{$\begin{array}{l}\text { Heart Weight } \\
\text { (g) }\end{array}$} & \multirow{2}{*}{$\begin{array}{l}\text { Gastrocnemius } \\
\text { Weight }(\mathrm{g})\end{array}$} \\
\hline BCAAs (mg/mL) & Exercise & & \\
\hline- & - & $0.14 \pm 0.01^{* \# \& \&}$ & $0.15 \pm 0.01^{\& \$ \wedge}$ \\
\hline 20 & + & $0.20 \pm 0.02^{+\$ \wedge}$ & $0.16 \pm 0.01^{\$ \wedge}$ \\
\hline 60 & + & $0.22 \pm 0.03^{+\& \$ \wedge}$ & $0.17 \pm 0.26^{\$ \wedge}$ \\
\hline- & + & $0.18 \pm 0.02^{+\#}$ & $0.18 \pm 0.01^{+\wedge}$ \\
\hline 20 & - & $0.15 \pm 0.01^{* \#}$ & $0.21 \pm 0.01^{+* \#}$ \\
\hline 60 & - & $0.15 \pm 0.01^{* \#}$ & $0.23 \pm 0.02^{+^{*} \# \&}$ \\
\hline
\end{tabular}

Values are expressed as mean \pm SEM. + indicates statistically significant difference with Sedentary group at $p<0.05,{ }^{*}$ indicates statistically significant difference with 20BCAA/Ex group at $p<0.05$, \# indicates statistically significant difference with 60BCAA/Ex group at $p<0.05$, \& indicates statistically significant difference with Ex group at $p<0.05$, $\$$ indicates statistically significant difference with 20BCAA group at $p<0.05, \wedge$ indicates statistically significant difference with 60BCAA group at $p<0.05$ 


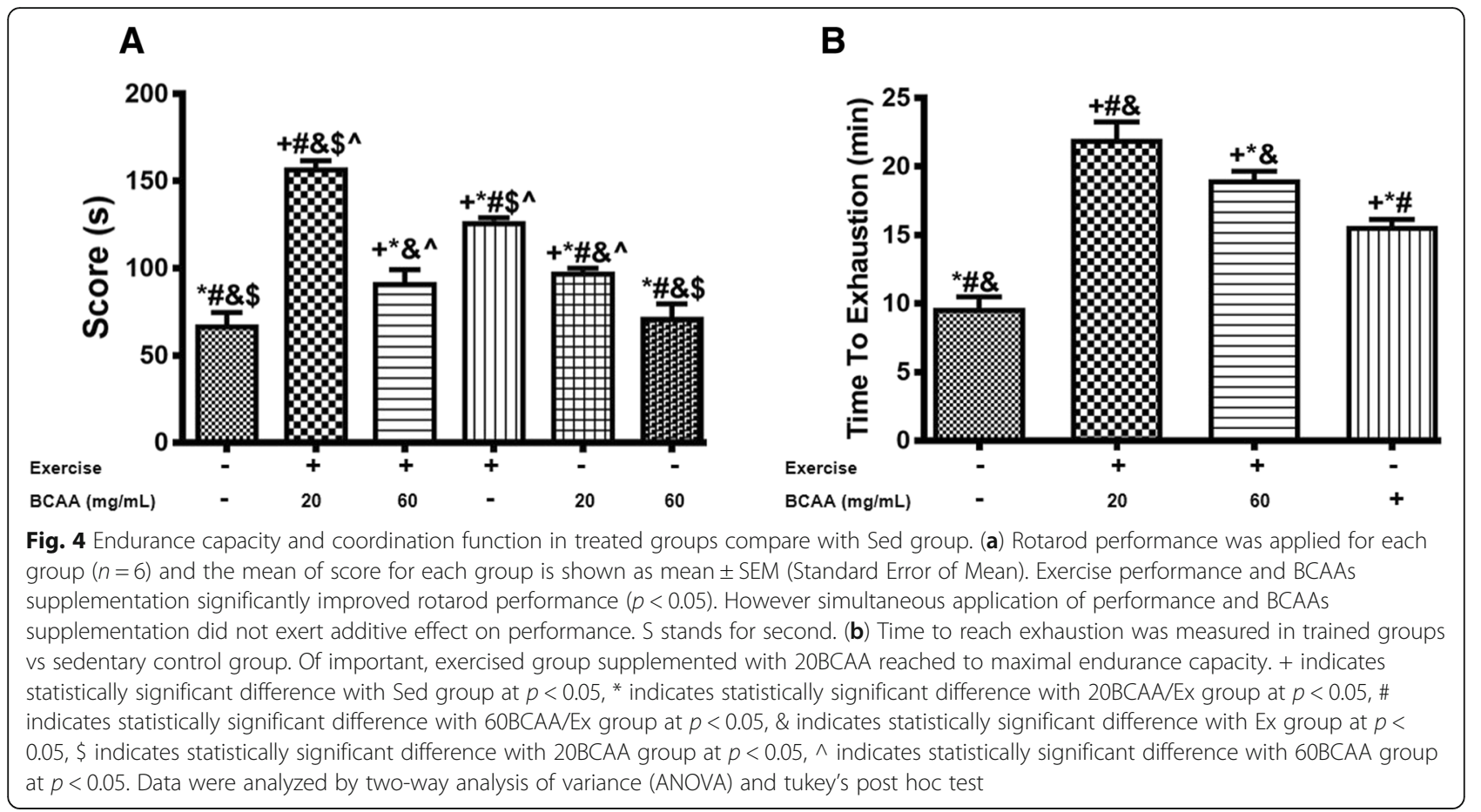

Upon eight weeks performance of tolerance and motor coordination test, 20BCAA/Ex group, got the highest score (Fig. 4a). Also by taking exhausting test, we indicated no improve in endurance capacity for 60BCAA/Ex group compared with 20BCAA/Ex group (Fig. 4b).
Effect of different concentrations of BCAA and aerobic exercise on FNDC5

Data revealed that Fndc5 expression was significantly increased in both, 20BCAA/Ex, and $60 \mathrm{BCAA} / \mathrm{Ex}$ comparing to Sed group (untrained without BCAAs intake -)

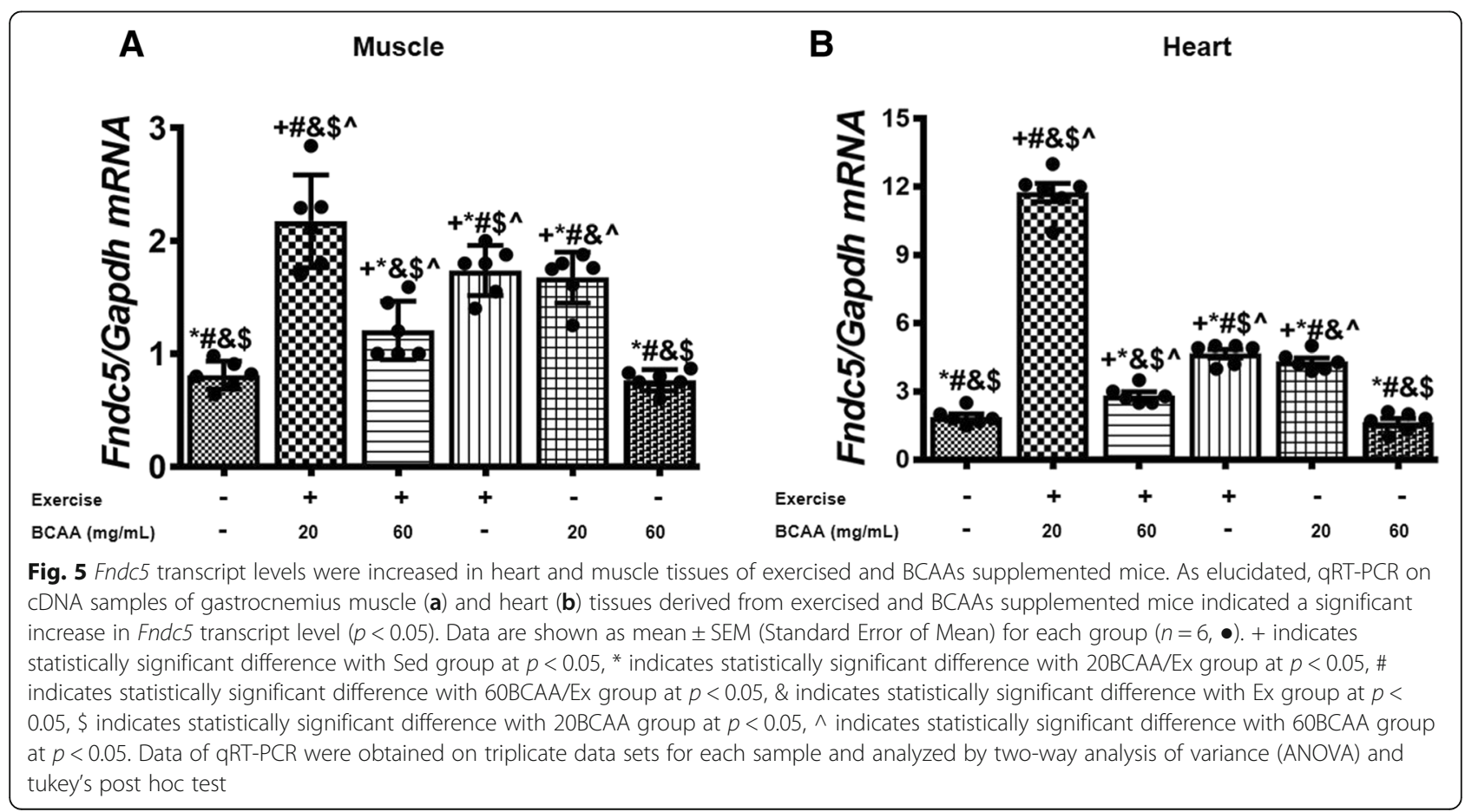




\section{Muscle}
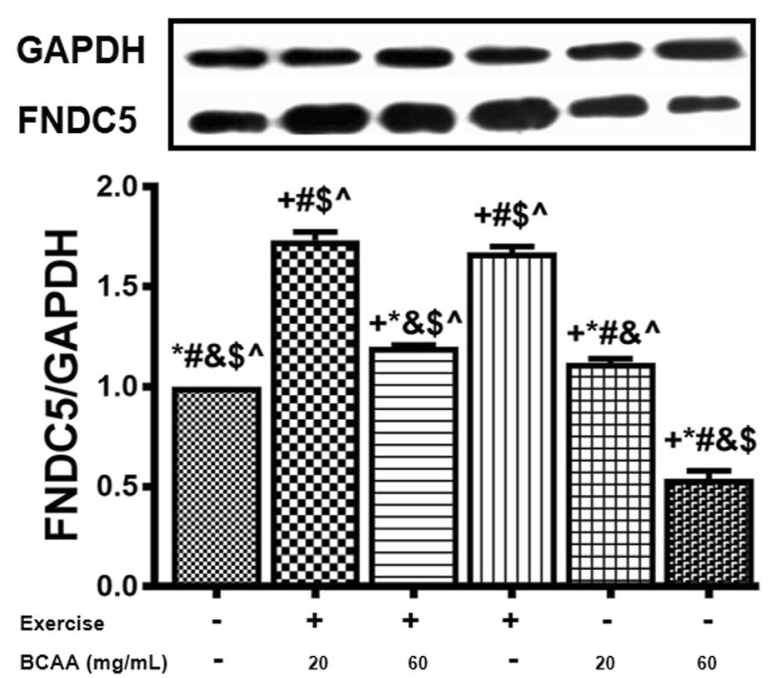

Fig. 6 Fndc5 protein contents were increased in gastrocnemius muscle tissue of exercised and BCAAs supplemented mice. Similar to what observed for the Fndc5 transcript levels, protein contents of FNDC5 was highest in 20BCAA/Ex group at $p<0.05$ as well as Ex group. Data are shown as mean \pm SEM (Standard Error of Mean) for each group $(n=6, \bullet)$. For better comparison, one of the immunoblots is shown above the diagram. + indicates statistically significant difference with Sed group at $p<0.05, *$ indicates statistically significant difference with 20BCAA/Ex group at $p<0.05$, \# indicates statistically significant difference with 60BCAA/Ex group at $p<0.05$, \& indicates statistically significant difference with Ex group at $p<0.05$, $\$$ indicates statistically significant difference with 20BCAA group at $p<0.05$, $\wedge$ indicates statistically significant difference with 60BCAA group at $p<0.05$. Data of western blotting were obtained on triplicate data sets for each sample and the intensity of each bond was quantified by image J. Two-way analysis of variance (ANOVA) and tukey's post hoc test were used for statistical analysis

in heart and gastrocnemius muscles (Fig. 5a, b). Interestingly, supplementation with $60 \mathrm{mg} / \mathrm{mL}$ BCAAs was not able to increase Fndc5 expression, while at lower concentration of BCAA (20 mg/mL) upregulated the expression of Fndc5 significantly (Fig. 5a, b). Furthermore, the highest increase in Fndc5 expression was accomplished when a combination of exercise was performed with $20 \mathrm{mg} / \mathrm{mL}$ BCAAs supplementation (20BCAA/Ex group) (Fig. 5a, b). In the gastrocnemius skeletal muscle, protein levels of FNDC5 were significantly higher in Ex and 20BCAA/Ex groups as compared to Sed group. Similar to the Fndc5 mRNA, protein content of FNDC5 was not up-regulated in 60BCAA group (Fig. 6).

BCAAs supplementation and aerobic exercise effects on the expression of genes involved in mitochondrial biogenesis

Additionally, we assessed the expression of mitochondrial genes in gastrocnemius and heart muscles. As expected, our data indicated that BCAAs increased the expression of mtDNA transcription factor A (Tfam), Cox4i1, a and b subunits of the mitochondrial $\mathrm{H}^{+}$-ATP synthase (a-F1-ATPase, b-F1-ATPase) in both of gastrocnemius and heart muscles (Figs. 7, 8, 9, 10). However, the maximum enhancement was yielded when BCAAs at concentration of $20 \mathrm{mg} / \mathrm{mL}$ (20BCAA) was supplemented. Of important the effect of exercise was not significant with BCAAs supplementation (Figs. 7, 8, 9, 10). A similar trend of modulation in transcripts levels of aforementioned genes was obtained in heart tissue of the mice (Figs. 7, 8, 9, 10). As these genes are under regulation of Pgc- $1 \alpha$, we assessed transcript level of $P g c-1 \alpha$ in both gastrocnemius and heart tissues. Again, the same trend was observed for $P g c-1 \alpha$ expression in both heart and muscle tissues (Fig. 11). Exercise (Ex) increased transcript levels of $P g c-1 \alpha$ (Fig. 11), whereas maximal increase in $P g c-1 \alpha$ mRNA was yielded when $20 \mathrm{mg} / \mathrm{mL}$ BCAAs supplemented (20BCAA) (Fig. 11). Importantly, no significant modulation in Pgc-1 $\alpha$ transcript levels was observed when higher amount of BCAAs $(60 \mathrm{mg} / \mathrm{mL})$ [60BCAA] was implemented (Fig. 11). Data revealed that increased expression of $P g c-1 \alpha$ due to the administration of $20 \mathrm{mg} / \mathrm{mL}$ BCAAs (20BCAA) was more than exercise (Ex) (Fig. 11). Notably, we found that Sirt1 mRNA was increased in 20BCAA/Ex group, the same as Fndc5 mRNA in gastrocnemius and heart muscle (Fig. 12). To our knowledge, $P g c-1 \alpha$ is known as the co-activator of PPAR . Data indicated that PPAR gene expression was significantly increased in exercise group (Ex) (Fig. 13). Interestingly, administration of $60 \mathrm{mg} / \mathrm{mL}$ BCAAs during the exercise (60BCAA/Ex) decreased transcript levels of PPARY (Fig. 13). However supplementation of $20 \mathrm{mg} / \mathrm{mL}$ BCAAs with exercise (20BCAA/Ex) significantly increased the expression of PPARY (Fig. 13). Moreover, high amount of BCAAs $(60 \mathrm{mg} / \mathrm{mL})$ [60BCAA] administration reversed the expression of $P P A R \gamma$ (Fig. 13).

\section{Correlation analysis of circulating irisin with muscle and heart Fndc5 mRNAs}

The impact of exercise on plasma levels of irisin was later investigated by ELISA. As depicted, ELISA results revealed that plasma concentration of irisin significantly was changed in mice 20BCAA/Ex and EX groups compared to Sed group (Fig. 14a). Correlation of irisin levels with Fndc5 revealed that circulating irisin had positive associations ( $r=$ 0.65 and 0.7 for muscle and heart respectably) with the expression of this gene (Fig. 14b, c). Interestingly, increased amount of plasma irisin was related to the increased expression level of Fndc5 in 20BCAA/Ex group.

Plasma profile of lactate and urea in exercised and BCAAs supplemented mice

Meanwhile, lactate and urea content in plasma increased significantly in 60BCAA/Ex group (Fig. 15). Importantly, 


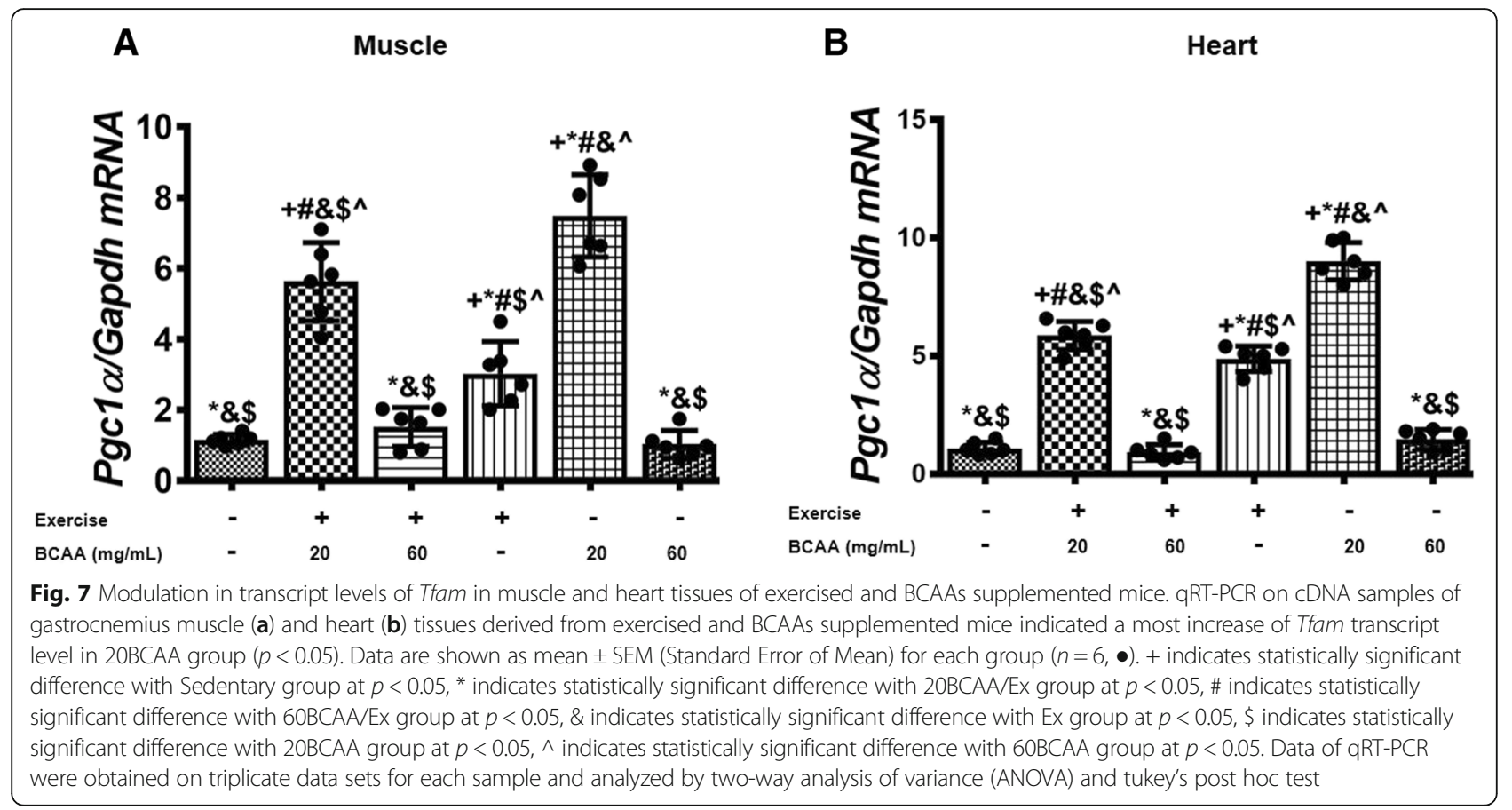

we did not observe any significant change in aforementioned parameters in 20BCAA/Ex group. Consistently, in 20BCAA/Ex group whole endurance capacity in treadmill tests was improved (Fig. $4 \mathrm{~b}$ ) as well as better performance on motor coordination test (Fig. 4a).

\section{Discussion}

Our results indicated that BCAAs supplementation increased body weight, heart and gastrocnemius muscle weight. As it was earlier reported, BCAAs supplementation promotes protein synthesis and inhibits protein

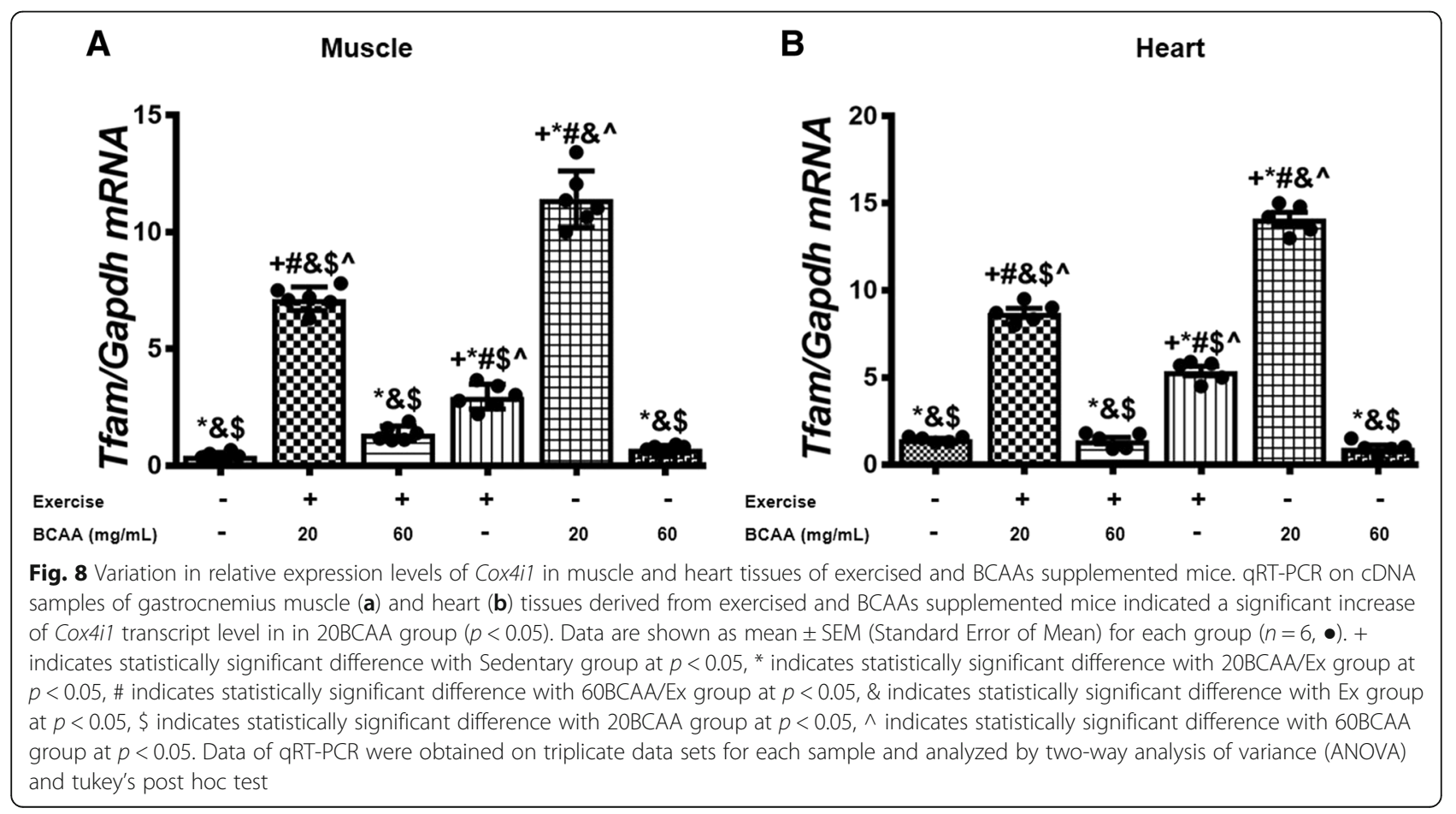




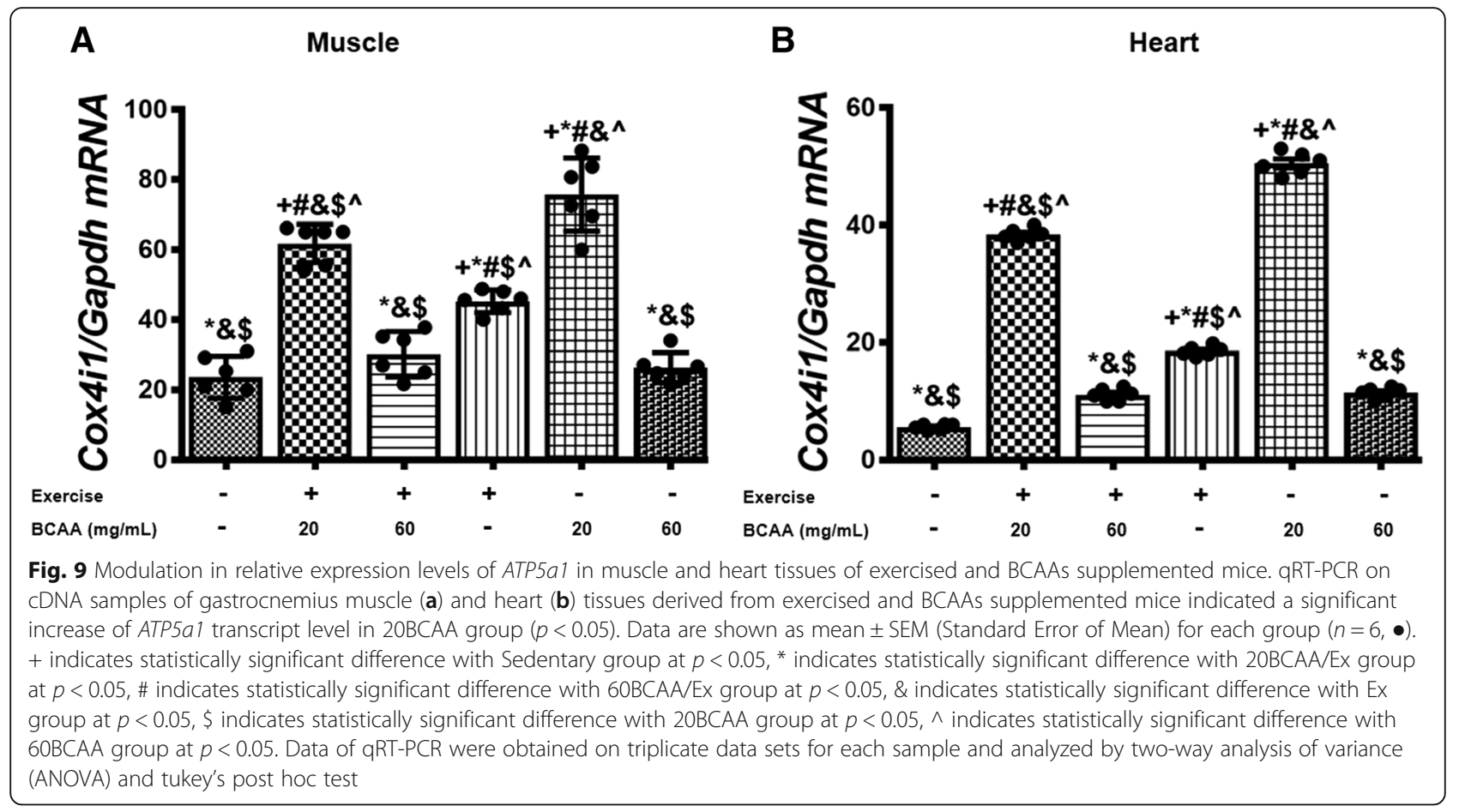

degradation via mTOR pathway, therefore increases muscle and heart weight [6] Also, importance of cardiac BCAAs catabolism and functional impact on cardiac development and physiology is well recognized [28]. D'Antona et al. indicated that BCAAs supplementation increases mitochondrial biogenesis through $P g c-1 \alpha$ and
Sirt1 expression in primary cardiac and skeletal myocytes, which is accompanied by enhanced physical endurance They also demonstrated BCAAs supplemented mice was accompanied by enhanced mitochondrial biogenesis and function in cardiac and skeletal muscles but not in liver or fat. They showed that BCAAs

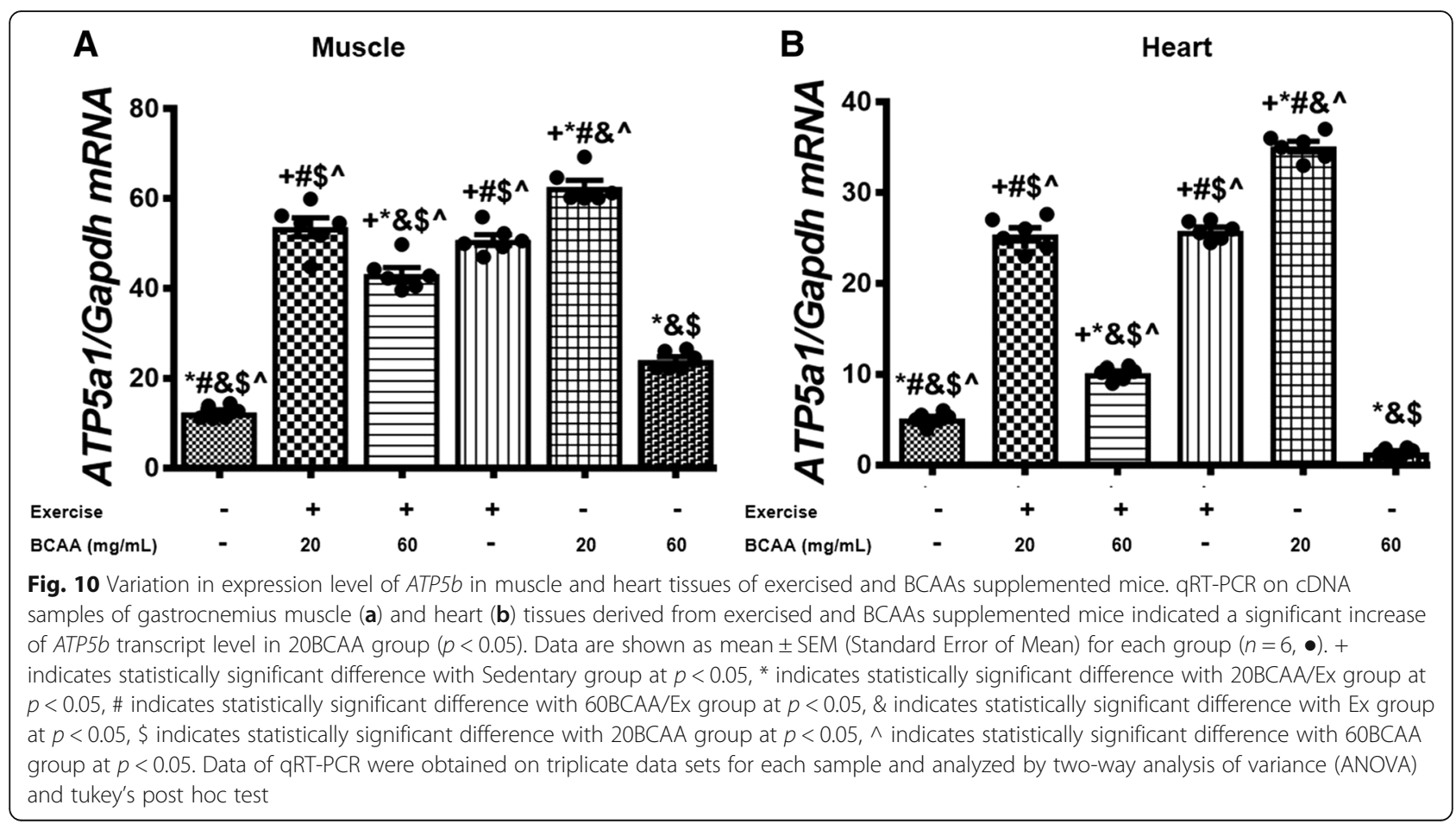




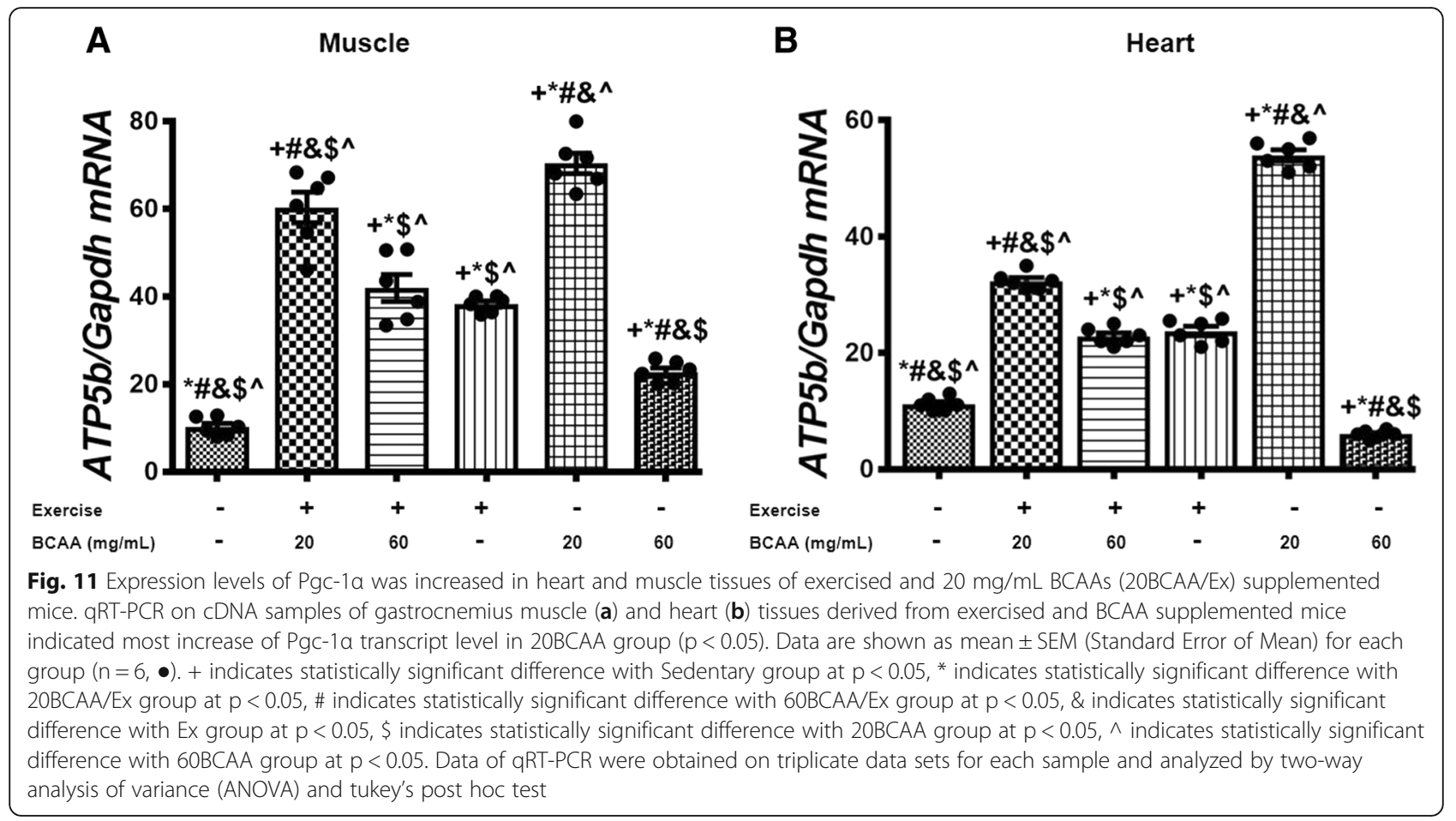

activated mTOR signaling and could enhance mitochondrial biogenesis [10].

Physical exercise is a well-recognized factor that could increase $F n d c 5$ gene expression [14, 21, 30]. Our results confirmed such concept as exercise increased transcript level of muscle and heart Fndc5. Interestingly BCAAs $(20 \mathrm{mg} / \mathrm{mL})$ supplementation (20BCAA) was beneficial to increase the transcript level of Fndc5. However, higher amount of BCAAs $(60 \mathrm{mg} / \mathrm{mL})$ did not change Fndc5 transcript level even though the expression of mitochondrial genes decreased. This is possibly due to triggering an increase in energy expenditure [30]. Furthermore, elevated circulating BCAAs levels have been correlated with severity of insulin resistance. It is

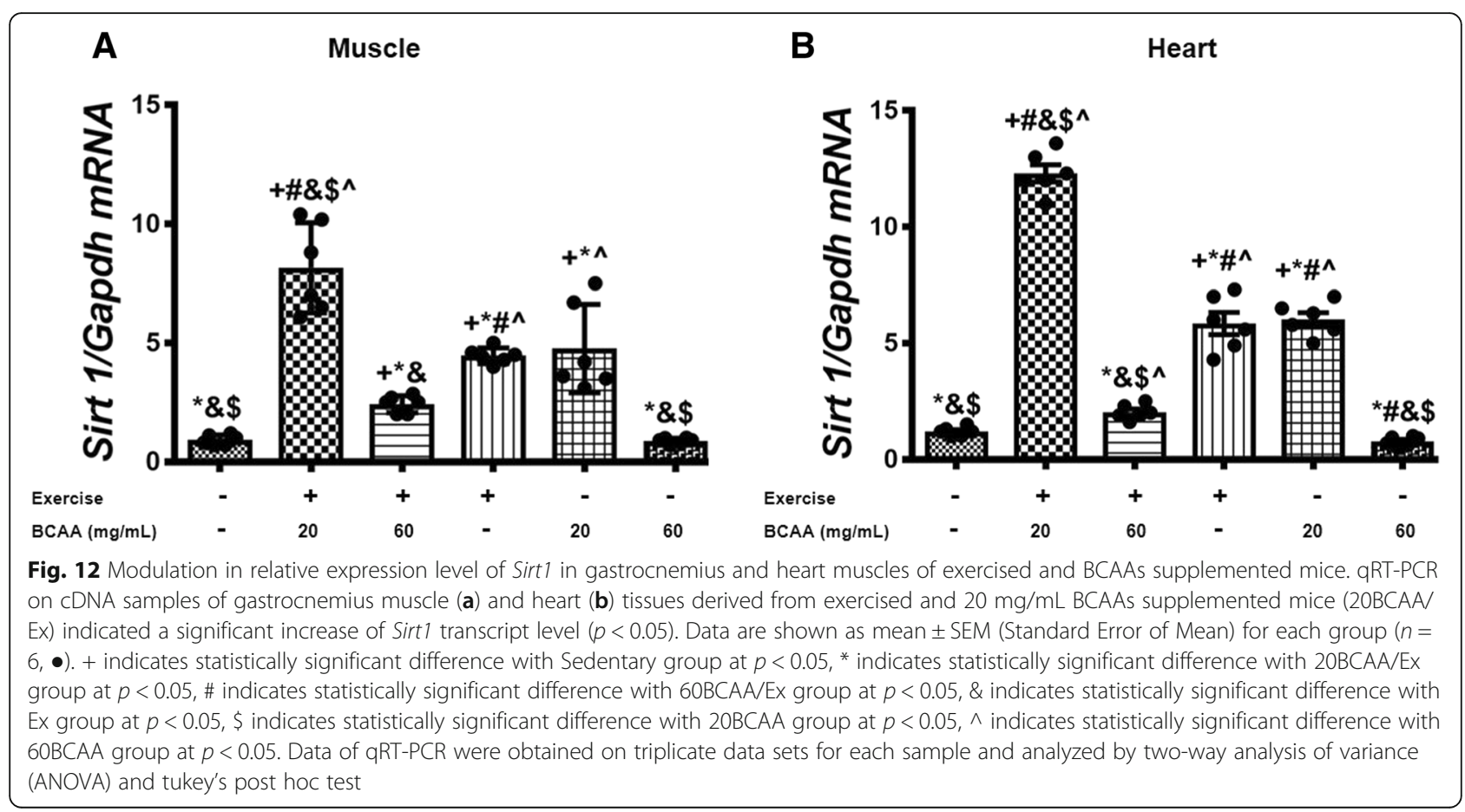




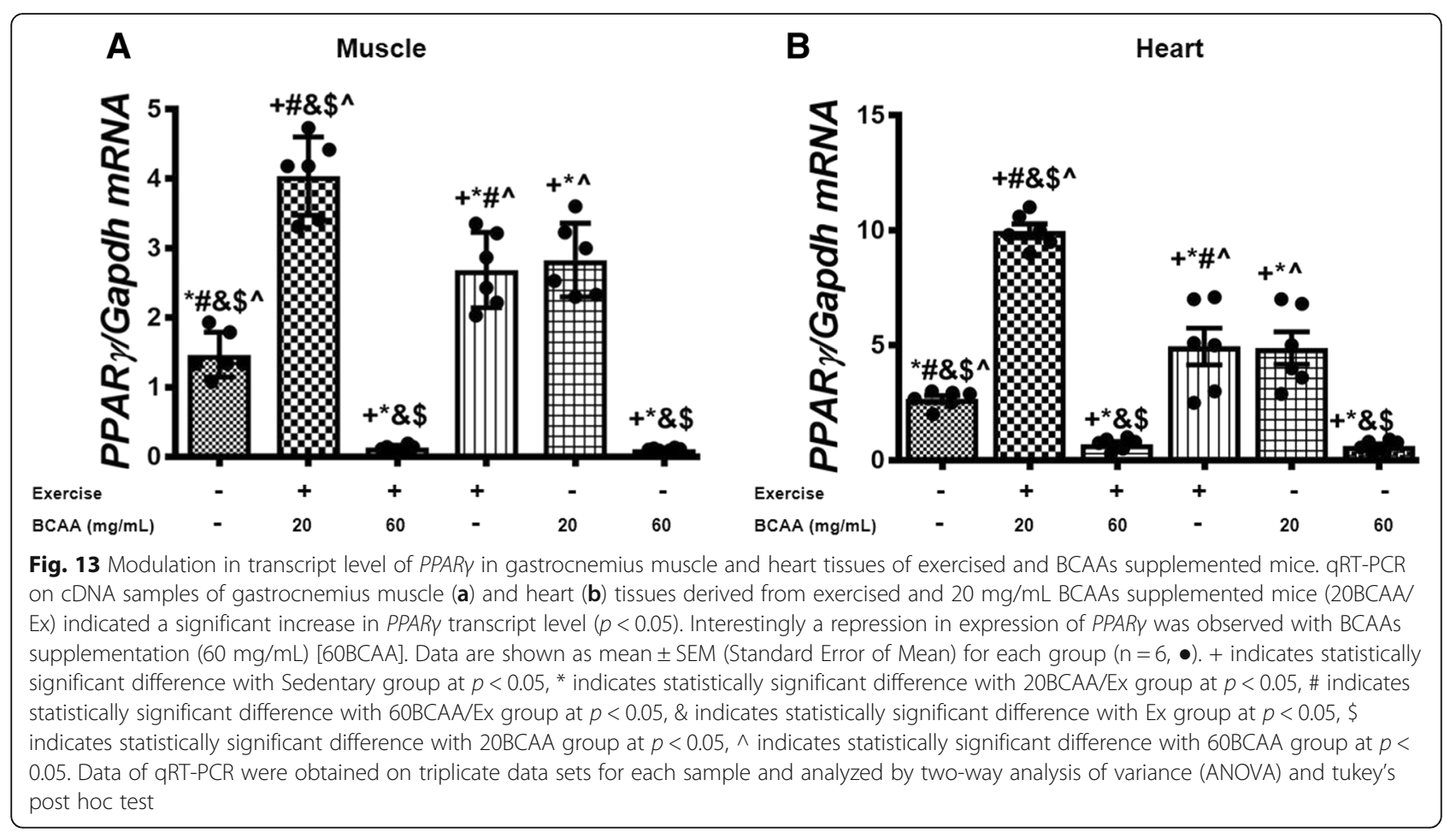

hypothesized that elevated circulating BCAAs observed in insulin resistance may result from dysregulated BCAAs degradation. Moreover BCAAs metabolism results in an accumulation of toxic BCAAs metabolites, then in turn trigger the mitochondrial dysfunction and stress signaling associated with insulin resistance despite of increment in mitochondrial content and enhancement of oxidative capacity in skeletal muscle [29, 31]. Detailed molecular mechanism of BCAAs overdose on Fndc5 gene expression in the skeletal and heart muscles remains to be obscure.

Additionally, the synergetic effect of exercise interaction with $20 \mathrm{mg} / \mathrm{mL}$ BCAAs supplementation (20BCAA/Ex) on induction of Fndc5 transcription was evident in our data. We found this interaction had positive effect on Fndc5 expression and metabolism. Also, we indicated protein content of FNDC5 decreased in 60BCAA as compared with sedentary group. Interestingly, we observed the protein level of FNDC5 in the skeletal muscle was higher in exercised mice in contrast with 20BCAA group. Presumably, this incompatibility between mRNA and protein levels of FNDC5 in the mice is related to the activity of some regulators which affect protein translation [32, 33].

Our findings were in good agreement with Aydin et al. which reported a positive association with metabolism and $F n d c 5$ gene expression [21]. Unlike our findings, Pekkala et al. indicated no significant up-regulation in Fndc5 of skeletal muscle in trained individuals [34]. This discrepancy may be mainly due to the type of exercise or simply reflecting differences between human and mice metabolism. The secretory type of Fndc5 is irisin, which affects total body energy expenditure, as well as browning of WAT (white adipose tissue) [14]. There are several controversy results about Fndc5 and irisin levels in plasma [13, 14, 16, 21, 35]. Our data showed irisin level was increased in 20BCAA/Ex group. Therefore, we assume that, irisin is increased in response to exercise and $20 \mathrm{mg} / \mathrm{mL}$ of dietary BCAAs.

$P g c-1 \alpha$, is a co-activator of various nuclear receptors as well as transcription factors. Previous study has indicated that $P g c-1 \alpha$ is involved in regulation of energy metabolism, as well as thermogenesis, in skeletal muscle. In skeletal muscle, $P g c-1 \alpha$ regulates not only the mitochondrial function but also metabolic activity of the cell [36, 37]. Tadaishi et al. revealed that, BCAAs metabolism mainly occurs in mitochondria of skeletal muscle and is induced by $\operatorname{Pgc}-1 \alpha$ [36]. However, higher amount of BCAAs $(60 \mathrm{mg} / \mathrm{mL})$ reversed such inductive responses, possibly by increased BCAAs catabolic flux which triggers insulin resistance in myoblast [38].

In this study we have examined the effect of exercise and BCAAs supplementation on transcript levels of Sirt 1 PPARy, Pgc-1a, Tfam, Cox4i1, ATP5a1, ATP5b and Fndc5 involved in mitochondrial biogenesis and for the first time we have shown that endurance exercise cold increase ATP5 $a$ and ATP5b mRNA expression. In present study, we have demonstrated that Sirt 1 and Fndc5 mRNA had a similar trend and they had a positive correlation with each other. PPARY expression was 


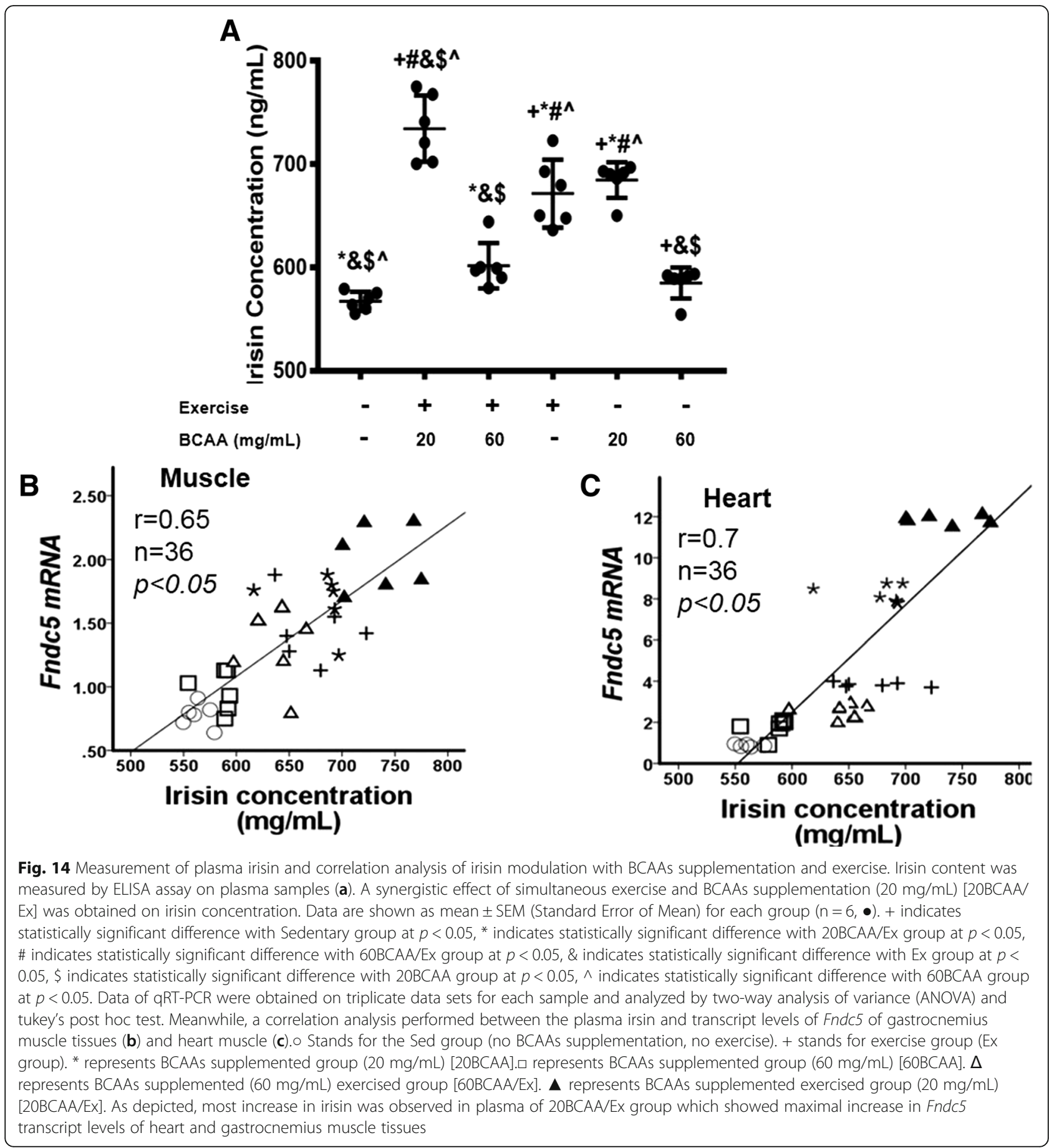

observed in trained mice, emphasizing that exercise could enhance PPARy gene expression [38]. Our results are in agreement with the previous study which indicated Sirt1 up-regulation and life span extension, and increasing in mitochondrial biogenesis, and ROS production decrease in the skeletal muscle of male mice [10]. One of the limitation of our study was lack of data about no mitochondrial related functional evidences in either tissues, such as mitochondrial number, respiration capacity, $\beta$-oxidation to support the physiological observation of BCAAs overload. This is critical issue which should be investigated in further experiments.

According to our knowledge endurance exercise increases the capacity of skeletal muscle for aerobic metabolism through an increase in mitochondrial capacity to generate ATP via oxidative phosphorylation [39], presumably through upregulation of $P g c-1 \alpha$ and PPAR $\gamma$ expression [40]. Furthermore, BCAAs supplementation may improve 


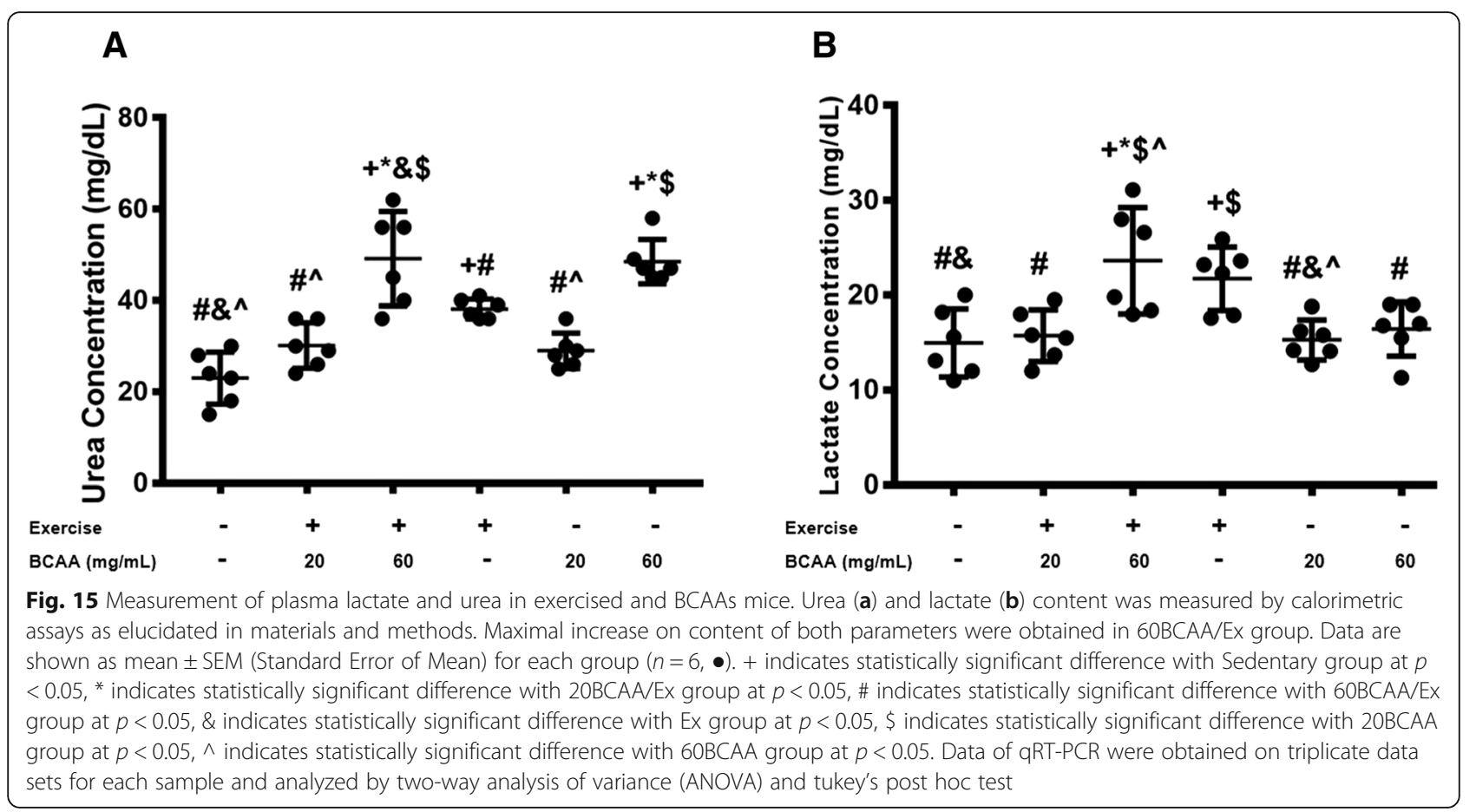

muscle fiber size, physical endurance and it may increase mitochondrial activity as already shown that treatment with BCAAs in mice caused significant increase in Pgc-1 $\alpha$, Tfam and Sirt1 expression in skeletal muscle. Furthermore, BCAAs supplementation is responsible for antioxidant defense and reduction of ROS [10]. Enhancement of $P g c-1 \alpha$ expression triggers the interaction of Pgc- $1 \alpha$ with PPAR $\gamma$, which elaborates the oxidative capacity of mitochondria. On the other hand, Pgc- $1 \alpha$ mediates BCAAs metabolism in skeletal muscle through increasing the transcript levels of branched chain amino acid transaminase 1(Bcat1), Bcat2 and branched-chain alpha-keto acid dehydrogenase (Bckdh) [41]. Increment in BCAAs catabolism leads to an increase of cellular Acetyl-CoA, Acetoacetate, and Soccinyl-CoA which reduces glucose oxidation rate and lactate production $[36,39]$. Final response of the myoblast to these events is the up-regulation of Fndc5 through unidentified cascade.

\section{Conclusion}

Our present study suggests that consuming $20 \mathrm{mg} / \mathrm{mL}$ BCAAs with exercise (20BCAA/Ex) had positive effect on expression level of gastrocnemius muscle Fndc5, PPARy, $P g c-1 \alpha$ similar with heart tissue. In addition, Irisin levels were increased at most level after $20 \mathrm{mg} / \mathrm{mL}$ BCAAs supplementation which coincided with the exercise (20BCAA/ Ex). However, overloading of higher amount of BCAA may have adverse these effects on transcript levels of Fndc5. However, physiological aspects of this finding needs to be confirmed in further studies.

\section{Additional file}

Additional file 1: Figure S1. Comparative study on amino acid content of proteins in human and mouse. As shown, the assessed proteins were the same as were obtained by STRING analysis (Fig. 2). Dark color indicates more homology in amino acid residues and bright red color represents more dissimilarity between human and mouse proteins. Of interest most similarity was obtained for PPARY, and FNDC5 between mouse and human. (JPG $86 \mathrm{~kb}$ )

\section{Abbreviations}

ANOVA: Analysis of variance; BBB: Blood-brain barrier; BCAAs: Branched chain amino acids; Bcat: Branched chain amino acid transaminase;

Bckdh: Branched-chain alpha-keto acid dehydrogenase; Ex: Endurance exercise training; FNDC5: Fibronectin type III domain containing 5;

Gapdh: Glyceraldehyde-3-phosphate dehydrogenase; mtDNA: Mitochondrial DNA; mTORC1: Mammalian target of rapamycin complex 1; NRF: Nuclear respiratory factor; Pgc-1a: Peroxisome proliferator-activated receptor gamma coactivator 1-alpha; PPARY: Peroxisome proliferator-activated receptor gamma; qRT-PCR: Quantitative real-time PCR; SEM: Standard error of mean; Sirt1: Sirtuin 1; TFAM: Mitochondrial transcription factor A; TG: Triglyceride; WAT: White adipose tissue

\section{Acknowledgements}

We thank our colleagues for their association and helpful discussions in this study. Authors are grateful to Mrs. Jamileh Mahdavinia (Kerman University of Medical Sciences, Iran) for revising the text of manuscript.

\section{Funding}

There was no funding to support this study.

\section{Availability of data and materials}

All of the raw data and the rest of materials are remained in Royan Institute for Biotechnology and are available upon request.

Authors' contributions

Design of study was done by NA, KG, FT and MHNE and experiments was performed by NA., Analyses and data mining were performed by NA, IN, FR 
and ST technical assistances were performed by ZS, FR and ST. Interpretation of the obtained information was done by NA, KG, FT and MHNE. The manuscript was written by NA and KG and was approved by FT and MHNE. All authors read and approved the final manuscript.

\section{Ethics approval}

Approval of mouse usage in this study was obtained by the Ethics committee of Royan Institute.

\section{Consent for publication}

All authors support submission to this journal.

\section{Competing interests}

The authors declare that they have no competing interests.

\section{Publisher's Note}

Springer Nature remains neutral with regard to jurisdictional claims in published maps and institutional affiliations

\section{Received: 14 April 2018 Accepted: 5 August 2018 Published online: 29 August 2018}

\section{References}

1. Harris RA, Joshi M, Jeoung NH, Obayashi M. Overview of the molecular and biochemical basis of branched-chain amino acid catabolism. J Nutr. 2005; 135:1527S-30S.

2. Ra S-G, Miyazaki T, Ishikura K, Nagayama H, Komine S, Nakata Y, et al. Combined effect of branched-chain amino acids and taurine supplementation on delayed onset muscle soreness and muscle damage in high-intensity eccentric exercise. J Int Soc Sports Nutr. 2013;10:51.

3. Falavigna G, JAdA J, Rogero MM, ISdO P, Pedrosa RG, Junior EM, et al. Effects of diets supplemented with branched-chain amino acids on the performance and fatigue mechanisms of rats submitted to prolonged physical exercise. Nutrients. 2012;4:1767-80.

4. Babij P, Matthews S, Rennie M. Changes in blood ammonia, lactate and amino acids in relation to workload during bicycle ergometer exercise in man. Eur J Appl Physiol Occup Physiol. 1983;50:405-11.

5. Jin G, Kataoka Y, Tanaka M, Mizuma H, Nozaki S, Tahara T, et al. Changes in plasma and tissue amino acid levels in an animal model of complex fatigue. Nutrition. 2009;25:597-607.

6. Duan Y, Li F, Li Y, Tang Y, Kong $X$, Feng Z, et al. The role of leucine and its metabolites in protein and energy metabolism. Amino Acids. 2016;48:41-51.

7. Nishida Y, Ide Y, Okada M, Otsuka T, Eguchi Y, Ozaki I, et al. Effects of homebased exercise and branched-chain amino acid supplementation on aerobic capacity and glycemic control in patients with cirrhosis. Hepatol Res. 2016; 47(3):E193-E200.

8. Cheon W. Effect of leucine uptake on hepatic and skeletal muscle gene expression in rats: a microarray analysis. J Exerc Nutrition Biochem. 2015;19:139.

9. Arakawa M, Masaki T, Nishimura J, Seike M, Yoshimatsu H. The effects of branched-chain amino acid granules on the accumulation of tissue triglycerides and uncoupling proteins in diet-induced obese mice. Endocr J. 2011;58:161-70

10. D'Antona G, Ragni M, Cardile A, Tedesco L, Dossena M, Bruttini F, et al. Branched-chain amino acid supplementation promotes survival and supports cardiac and skeletal muscle mitochondrial biogenesis in middleaged mice. Cell Metab. 2010;12:362-72.

11. Iwasa M, Kobayashi Y, Mifuji-Moroka R, Hara N, Miyachi H, Sugimoto R, et al. Branched-chain amino acid supplementation reduces oxidative stress and prolongs survival in rats with advanced liver cirrhosis. PLoS One. 2013;8: e70309.

12. Moreno-Navarrete JM, Ortega F, Serrano M, Guerra E, Pardo G, Tinahones F, et al. Irisin is expressed and produced by human muscle and adipose tissue in association with obesity and insulin resistance. J Clin Endocrinol Metab. 2013;98:E769-E78.

13. Roca-Rivada A, Castelao C, Senin LL, Landrove MO, Baltar J, Crujeiras AB, et al. FNDC5/irisin is not only a myokine but also an adipokine. PLoS One. 2013;8:e60563

14. Boström P, Wu J, Jedrychowski MP, Korde A, Ye L, Lo JC, et al. A PGC1-[agr]dependent myokine that drives brown-fat-like development of white fat and thermogenesis. Nature. 2012;481:463-8.
15. Huh JY, Mougios V, Kabasakalis A, Fatouros I, Siopi A, Douroudos II, et al. Exercise-induced irisin secretion is independent of age or fitness level and increased irisin may directly modulate muscle metabolism through AMPK activation. J Clin Endocrinol Metab. 2014:99:E2154-E61.

16. Samy DM, Ismail CA, Nassra RA. Circulating irisin concentrations in rat models of thyroid dysfunction-effect of exercise. Metabolism. 2015; 64:804-13.

17. Puigserver P, Spiegelman BM. Peroxisome proliferator-activated receptor- $\gamma$ coactivator 1a (PGC-1a): transcriptional coactivator and metabolic regulator. Endocr Rev. 2003;24:78-90.

18. Geng T, Li P, Okutsu M, Yin X, Kwek J, Zhang M, et al. PGC-1a plays a functional role in exercise-induced mitochondrial biogenesis and angiogenesis but not fiber-type transformation in mouse skeletal muscle. Am J Phys Cell Phys. 2009;298:C572-C9.

19. Marycz K, Mierzejewska K, Śmieszek A, Suszynska E, Malicka I, Kucia M, et al. Endurance exercise mobilizes developmentally early stem cells into peripheral blood and increases their number in bone marrow: implications for tissue regeneration. Stem Cells Int. 2016;2016:5756901.

20. Yuan Y, Cruzat VF, Newsholme P, Cheng J, Chen Y, Lu Y. Regulation of SIRT1 in aging: roles in mitochondrial function and biogenesis. Mech Ageing Dev. 2016;155:10-21.

21. Aydin S, Kuloglu T, Aydin S, Eren MN, Celik A, Yilmaz M, et al. Cardiac, skeletal muscle and serum irisin responses to with or without water exercise in young and old male rats: cardiac muscle produces more irisin than skeletal muscle. Peptides. 2014;52:68-73.

22. Szklarczyk D, Morris JH, Cook H, Kuhn M, Wyder S, Simonovic M, et al. The STRING database in 2017: quality-controlled protein-protein association networks, made broadly accessible. Nucleic Acids Res. 2016;45(D1):D362-D368.

23. Boivin G, Platt K, Corbett J, Reeves J, Hardy A, Elenes E, et al. The effects of high-fat diet, branched-chain amino acids and exercise on female C57BL/6 mouse Achilles tendon biomechanical properties. Bone and Joint Research. 2013;2:186-92.

24. Schefer V, Talan MI. Oxygen consumption in adult and AGED C57BL/6J mice during acute treadmill exercise of different intensity. Exp Gerontol. 1996;31: 387-92.

25. Jang J, Yun H-Y, Park J, Lim K. Protective effect of branched chain amino acids on hindlimb suspension-induced muscle atrophy in growing rats. J Exerc Nutrition Biochem. 2015;19:183.

26. Ishizaki S, Nishiyama M, Hagiwara A. Long-term branched chain amino acid supplementation ameliorates diethylnitrosamine-induced liver glutathione Stransferase-p positivity in Zucker fatty rats. J Clin Exp Hepatol. 2013;3:192-7.

27. Zhenyukh $\mathrm{O}$, Civantos E, Ruiz-Ortega M, Sánchez MS, Vázquez C, Peiró C, et al. High concentration of branched-chain amino acids promotes oxidative stress, inflammation and migration of human peripheral blood mononuclear cells via mTORC1 activation. Free Radic Biol Med. 2017:104:165-77.

28. Huang $Y$, Zhou M, Sun $H$, Wang $Y$. Branched-chain amino acid metabolism in heart disease: an epiphenomenon or a real culprit? Cardiovasc Res. 2011; 90:220-3.

29. Gannon NP, Schnuck JK, Vaughan RA. BCAA metabolism and insulin sensitivityDysregulated by metabolic status? Mol Nutr Food Res. 2018;62:1700756.

30. Veldhorst MA, Westerterp-Plantenga MS, Westerterp KR. Gluconeogenesis and energy expenditure after a high-protein, carbohydrate-free diet. Am J Clin Nutr. 2009:90:519-26.

31. Lynch CJ, Adams SH. Branched-chain amino acids in metabolic signalling and insulin resistance. Nat Rev Endocrinol. 2014;10:723.

32. Bartel DP. MicroRNAs: genomics, biogenesis, mechanism, and function. cell. 2004;116:281-97.

33. Filipowicz W, Bhattacharyya SN, Sonenberg N. Mechanisms of post-transcriptional regulation by microRNAs: are the answers in sight? Nat Rev Genet. 2008;9:102.

34. Pekkala S, Wiklund PK, Hulmi J, Ahtiainen JP, Horttanainen M, Pöllänen E, et al. Are skeletal muscle FNDC5 gene expression and irisin release regulated by exercise and related to health? J Physiol. 2013;591:5393-400.

35. Blüher S, Panagiotou G, Petroff D, Markert J, Wagner A, Klemm T, et al. Effects of a 1-year exercise and lifestyle intervention on irisin, adipokines, and inflammatory markers in obese children. Obesity. 2014;22:1701-8.

36. Tadaishi M, Miura S, Kai Y, Kano Y, Oishi Y, Ezaki O. Skeletal muscle-specific expression of PGC-1a-b, an exercise-responsive isoform, increases exercise capacity and peak oxygen uptake. PLoS One. 2011;6:e28290.

37. Jang C, Oh SF, Wada S, Rowe GC, Liu L, Chan MC, et al. A branched-chain amino acid metabolite drives vascular fatty acid transport and causes insulin resistance. Nat Med. 2016;22:421. 
38. Thomas AW, Davies NA, Moir H, Watkeys L, Ruffino JS, Isa SA, et al. Exerciseassociated generation of PPARy ligands activates PPARy signaling events and upregulates genes related to lipid metabolism. J Appl Physiol. 2012;112: 806-15.

39. Hatazawa Y, Senoo N, Tadaishi M, Ogawa Y, Ezaki O, Kamei Y, et al. Metabolomic analysis of the skeletal muscle of mice overexpressing PGC-1a. PLoS One. 2015;10:e0129084.

40. Holloszy J. Regulation by exercise of skeletal muscle content of mitochondria and GLUT4. J Physiol Pharmacol. 2008;59:5-18.

41. Hatazawa Y, Tadaishi M, Nagaike Y, Morita A, Ogawa Y, Ezaki O, et al. PGC1a-mediated branched-chain amino acid metabolism in the skeletal muscle PLoS One. 2014;9:e91006.

Ready to submit your research? Choose BMC and benefit from:

- fast, convenient online submission

- thorough peer review by experienced researchers in your field

- rapid publication on acceptance

- support for research data, including large and complex data types

- gold Open Access which fosters wider collaboration and increased citations

- maximum visibility for your research: over $100 \mathrm{M}$ website views per year

At BMC, research is always in progress.

Learn more biomedcentral.com/submissions 